\title{
Article \\ Structural Insights into a Fusion Protein between a Glutaredoxin-like and a Ferredoxin-Disulfide Reductase Domain from an Extremophile Bacterium
}

\author{
Flavien Zannini ${ }^{1}\left(\mathbb{D}\right.$, Sandrine Mathiot ${ }^{2}$, Jérémy Couturier ${ }^{1,3}{ }^{\mathbb{D}}$, Claude Didierjean ${ }^{2, *}$ and Nicolas Rouhier ${ }^{1, * \mathbb{C}}$ \\ 1 Université de Lorraine, INRAE, IAM, F-54000 Nancy, France; flavien.zannini@univ-lorraine.fr (F.Z.); \\ jeremy.couturier@univ-lorraine.fr (J.C.) \\ 2 Université de Lorraine, CNRS, CRM2, F-54000 Nancy, France; sandrine.mathiot@univ-lorraine.fr \\ 3 Institut Universitaire de France, France \\ * Correspondence: claude.didierjean@univ-lorraine.fr (C.D.); nicolas.rouhier@univ-lorraine.fr (N.R.); \\ Tel.: +33-372745642 (C.D.); +33-372745157 (N.R.)
}

Citation: Zannini, F.; Mathiot, S.; Couturier, J.; Didierjean, C.;

Rouhier, N. Structural Insights into a Fusion Protein between a

Glutaredoxin-like and a

Ferredoxin-Disulfide Reductase

Domain from an Extremophile

Bacterium. Inorganics 2022, 10, 24.

https://doi.org/10.3390/

inorganics10020024

Academic Editor: Sandrine Ollagnier de Choudens

Received: 14 December 2021

Accepted: 14 February 2022

Published: 17 February 2022

Publisher's Note: MDPI stays neutral with regard to jurisdictional claims in published maps and institutional affiliations.

Copyright: (C) 2022 by the authors. Licensee MDPI, Basel, Switzerland. This article is an open access article distributed under the terms and conditions of the Creative Commons Attribution (CC BY) license (https:// creativecommons.org/licenses/by/ $4.0 /)$.

\begin{abstract}
In eukaryotic photosynthetic organisms, ferredoxin-thioredoxin reductases (FTRs) are key proteins reducing several types of chloroplastic thioredoxins (TRXs) in light conditions. The electron cascade necessary to reduce oxidized TRXs involves a pair of catalytic cysteines and a [4Fe-4S] cluster present at the level of the FTR catalytic subunit, the iron-sulfur cluster receiving electrons from ferredoxins. Genomic analyses revealed the existence of FTR orthologs in non-photosynthetic organisms, including bacteria and archaea, referred to as ferredoxin-disulfide reductase (FDR) as they reduce various types of redoxins. In this study, we describe the tridimensional structure of a natural hybrid protein formed by an N-terminal glutaredoxin-like domain fused to a FDR domain present in the marine bacterium Desulfotalea psychrophila Lsv54. This structure provides information on how and why the absence of the variable subunit present in FTR heterodimer which normally protects the Fe-S cluster is dispensable in FDR proteins. In addition, modelling of a tripartite complex based on the existing structure of a rubredoxin (RBX)-FDR fusion present in anaerobic methanogen archaea allows recapitulating the electron flow involving these RBX, FDR and GRX protein domains.
\end{abstract}

Keywords: ferredoxin-disulfide reductase; bacteria; hybrid protein; glutaredoxin-like protein

\section{Introduction}

Oxygenic photosynthesis uses solar energy to ensure the four-electron oxidation of water into dioxygen necessary to achieve carbon fixation. In the so-called linear electron transfer chain, electrons are transferred via photosystem II, plastoquinone, cytochrome b6/f, plastocyanin, and photosystem I. The primary electron-acceptor proteins present on the stromal side are ferredoxins (FDXs). They will distribute electrons to a plethora of proteins, the main routes being (i) for reducing NADP+ via ferredoxin-NADP reductase (FNR), (ii) for alimenting several chloroplastic enzymes, including the key sulfite reductase and nitrite reductase important for sulfate and nitrogen assimilation and (iii) for regulating the activity of carbon fixation enzymes notably those forming the Calvin-Benson cycle. In the latter case, electrons are transmitted from ferredoxins to a ferredoxin-thioredoxin reductase (FTR) that reduces several types of chloroplastic thioredoxins (TRXs) which control the redox state of many Calvin-Benson cycle enzymes [1,2]. In the lineage of photosynthetic organisms, FTR is a heterodimer formed by a conserved catalytic subunit of approximately $13 \mathrm{kDa}$ and a variable subunit with a molecular mass ranging from 7 to $13 \mathrm{kDa}$ [3]. The catalytic subunit contains six conserved cysteines, four being involved in the bridging of a [4Fe-4S] cluster and two forming an intramolecular disulfide in an oxidized form [4]. It has been proposed that the variable subunit protects the [4Fe-4S] cluster from its oxidative degradation by oxygen. Indeed, the recombinant heterodimer 
is purified fully repleted with its iron-sulfur cluster under aerobic conditions. The 3D structures of a Synechocystis FTR (SynFTR) were obtained; either alone, or in complex with Synechocystis FDX, or in complex with both Synechocystis FDX and spinach TRX-m or - $\mathrm{f}$ [4-6]. Moreover, the catalytic mechanism for TRX reduction was studied in detail and evidence for a novel type of $[4 \mathrm{Fe}-4 \mathrm{~S}]^{3+}$ cluster in FTR with five cysteine ligands was provided $[7,8]$.

Surprisingly, similar proteins are also present in bacteria and archaea that do not perform oxygenic photosynthesis [3,9]. In the genome of these organisms, there is no indication for the presence of a gene encoding the variable subunit likely suggesting that it is absent. In these organisms, the orthologous gene is often part of operons where $f d x$ and/or tr $x$-related genes are present [3]. Additionally, prior phylogenetic analyses pointed to the existence of at least seven FTR clades including genes coding for various hybrid proteins consisting of a FTR domain fused at the N- or C-terminal part of other redox active domains [9]. This highlights the existence of an important diversity within this protein family. In Methanosarcina species, anaerobic methanogen archaea, two FTR-like proteins named ferredoxin-disulfide reductase (FDR) 1 and 2 exist. The FDR1 consists of a single FDR domain whereas FDR2 is a natural fusion between a FTR and a rubredoxin (RBX) domain [10,11]. According to their presence in a single operon, the Methanosarcina barkeri FDR1 was shown to reduce a thioredoxin-like protein called $\mathrm{NrdH}$ which itself supports the in vitro nucleotide reduction activity of NrdD3, the oxygen-sensitive class III ribonucleotide reductase (RNR) present in these organisms [10]. Unlike FDR1, the Methanosarcina acetivorans FDR2 seems unable to reduce $\mathrm{NrdH}$ [10]. In the head-to-tail homodimer of $M$. acetivorans FDR2, the rubredoxin domain was found opposite to the catalytic disulfide/cysteine pairs and it was proposed to mediate electron transfer from a ferredoxin moiety to the [4Fe-4S] cluster of FDR [11]. Among the redoxins present in this species, i.e., seven TRXs (TRX1 to 7) and a glutaredoxin-like protein referred to as methanoredoxin (MRX) [12,13], only TRX5 and MRX were efficiently reduced by FDR1 in vitro [11]. Hence, while FDX seems to serve as an electron donor for both FDRs, an important specificity exists at the level of the electron acceptor. Interestingly, in M. acetivorans genome, the MRX-encoding gene is adjacent to the one encoding FDR2 which further support the functional connection between these proteins.

In a genomic search for natural fusion proteins possessing FTR/FDR domains, we noticed the existence of proteins formed by a glutaredoxin (GRX)-like domain fused to a FDR domain in a few organisms and even two representatives in Desulfotalea psychrophila Lsv54, a marine sulfate-reducing delta-proteobacterium, the genome of which was sequenced in 2004 [14]. This prompted us to express one of the GRX-FDR proteins from this species, that we referred to as DpGRX-FDR1, as a recombinant protein in Escherichia coli in order to study its structural properties. The crystal structure expands the information derived from previous studies of plant-type FTR and chloroplastic TRXs. It provides notably novel information regarding the interaction of FDR proteins with the electron-accepting redoxin partner and about the structural differences between FTR and FDR at the origin of the Fe-S cluster stability.

\section{Results}

\subsection{Several Natural Hybrid Proteins Contain a Ferredoxin-Thioredoxin Reductase-like Domain Fused to Redox Active Domains}

The existence of hybrid proteins in specific organisms or phyla is often synonymous with the functional association in organisms in which the constituting protein domains are expressed as separate proteins. We have interrogated the pfam, CDART and STRING databases using the respective family accession codes (PF02943, cl01977, COG4802) specific to the FTR/FDR family to obtain a detailed view of the associated protein domains. Protein sequences corresponding to FTR/FDR alone were clearly predominant both in photosynthetic and non-photosynthetic organisms, but we have noticed the existence of various natural fusion proteins in several bacteria and archaea. Although there were some- 
times differences in annotations and number of sequences, all these databases reported the existence of fusion proteins between FDR and a rhodanese domain (FDR-RHD), between FDR and a RBX or rubrerythrin domain either at the N- or C-terminal side, and between glutaredoxin-like or thioredoxin-like proteins and FDR (GRX-FDR or TRX-FDR) (Figure 1a). Additional evidence about the functional relationship between these protein domains come from the gene clustering that is also visible between FDR and members of these three gene families in some organisms. The FDR-RHD fusions are mostly present in the epsilon proteobacteria class; in the Campylobacterale and Nautiliale orders, the FDR-RBX fusions in archaea of the Euryarcheota phylum and in bacteria of the Chloroflexi and Spirochaete phyla, the TRX-FDR fusions in archaea of the Euryarcheota phylum and in some unclassified Parcubacteria and Candidatus bacterial groups and the GRX-FDR fusions in the delta proteobacteria class in the Desulfobacterale order.

By interrogating previous databases and the JGI-Integrated microbial genomes and microbiomes portal, we ended up with 12 GRX-FDR sequences, 10 in Desulfobacterales but also 2 in Nitrospira species (Figure 1b). In all these proteins, the cysteines of the FDR domain are present in the typical CPC, CPC and CxC motifs also present in regular FTRs. On the contrary, the intervening residues between both cysteines present in the CxxC motif of the GRX-like domain are more variable. Moreover, not all sequences bear a dithiol motif and among the two GRX-FDR fusions present in Desulfotalea psychrophila Lsv54, DpGRX-FDR1 possesses a CGFC signature, reminiscent of CGYC/CPFC and/or CGFS motifs frequently found in typical GRX whereas DpGRX-FDR2 possesses a CSYS motif which is less frequently encountered but is similar for instance to the one present in chloroplastic GRXS12 from plants and in yeast Grx6 [15,16].

\subsection{The Recombinant DpGRX-FDR1 Expressed in Escherichia coli Is a [4Fe-4S] Cluster-Bound Homodimer}

We have selected the DpGRX-FDR1 fusion from D. psychrophila for further studies. The recombinant protein corresponding to the full-length, 196 amino acid long, protein was expressed in E. coli and purified to homogeneity under aerobic conditions. In addition to the polypeptide absorption band present at $280 \mathrm{~nm}$, the UV-visible absorption spectrum of the as-purified protein exhibited two broad additional absorption bands, with maxima at $320 \mathrm{~nm}$ and $410 \mathrm{~nm}$ (Figure 2a). Analytical analysis of acid-labile sulfide and iron content revealed the presence of $3.3 \pm 0.3$ sulfur atoms and $4.0 \pm 0.1$ iron atoms per monomer, thus indicating that the protein contains a [4Fe-4S] cluster as all FTR/FDR characterized so far. Analytical gel filtration analysis revealed that the protein eluted with an apparent molecular mass of $47,060 \mathrm{kDa}$, which is interpreted as the exclusive presence of a dimeric form, based on the theoretical molecular mass of the monomer $(22,663 \mathrm{kDa})$ (Figure $2 \mathrm{~b})$.

The air-oxidized cluster present in DpGRX-FDR1 was tentatively reduced using dithionite or using an enzymatic system formed by NADPH and catalytic amounts of Chlamydomonas reinhardtii FNR and Synechocystis FDX, a system that proved efficient to reduce plant-type FTR in a previous study [17]. Using both systems, a decrease of the absorption in the 400 to $500 \mathrm{~nm}$ region was visible, which is consistent with Fe-S cluster reduction (Figure 3a). The NADPH-coupled reduction of DpGRX-FDR1 was also assessed over a time-course experiment (Figure $3 b$ ) and confirmed the capacity of a plant-type [2Fe-2S] cluster-containing FDX to reduce the [4Fe-4S] cluster present in DpGRX-FDR1.

Both the FDR and GRX domains were expressed separately either as untagged or 6-His tagged protein but only the constructs for the GRX domain led to the expression of a soluble protein. The E. coli cells were visibly brown in color and thus the His-tagged protein was purified by affinity chromatography under anaerobiosis since the Fe-S cluster present in most regular GRX is air-labile [18]. The UV-visible absorption spectrum of the as-purified GRX protein exhibited absorption bands, with maxima at 330, 416 and $460 \mathrm{~nm}$, which are typical of the presence of [2Fe-2S] clusters (Figure S1). Analytical analysis of acid-labile sulfide and iron content revealed the presence of $1.2 \pm 0.1$ sulfur atoms and $0.85 \pm 0.04$ 
iron atoms per monomer, which would be consistent with the presence of a [2Fe-2S] cluster in a dimer as in most Fe-S cluster containing GRXs characterized so far $[18,19]$.

CXxGSR

a

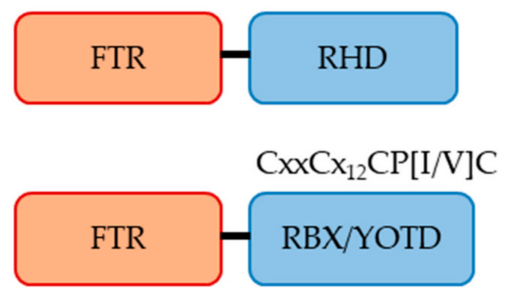

$\mathrm{CxVCx}_{12} \mathrm{CPTC}$
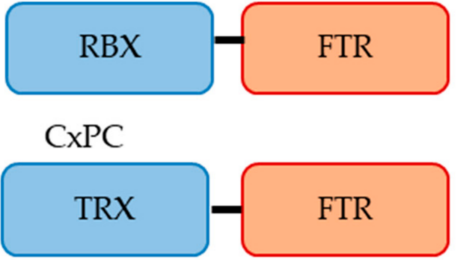

$\mathrm{Cx}[\mathrm{F} / \mathrm{Y}] \mathrm{C}$

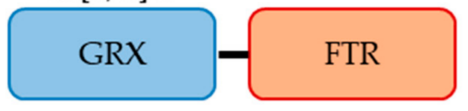

b

DPGRX-FDR1 DFRX-FDR2 Nt SGRX-FDR1 Dsb2GRX-FDR NT SGRX-FDR2 Dsp8GRX-FDR DsaGRX-FDR Dsp5GRX-FDR Dsp6GRX-FDR DS $f G R X-F D R$ DSB1GRX-FDR DsbGRX-FDR

DpGRX-FDR 1 DPGRX-FDR2 Nt SGRX-FDR 1 Dsb2GRX-FDR Nt sGRX-FDR2 Dsp8GRX-FDR DsaGRX-FDR Dsp5GRX-FDR Dsp6GRX-FDR DsfGRX-FDR Dsb1GRX-FDR DsbGRX-FDR

DpGRX-FDR1 DpGRX-FDR2 Nt SGRX-FDR 1 Dsb2GRX-FDR Nt SGRX-FDR2 Dsp8GRX-FDR DsaGRX-FDR Dsp5GRX-FDR Dsp6GRX-FDR DS $f G R X-F D R$ Dsb1GRX-FDR DsbGRX-FDR
MTDKKIVLYSLTTCGFCQAIKKMFDDLAVGHLCIQADELTGEEKKOALRDLRKVNPKCSFPTVVID MVKVKLYATAKCSYSOSIKKI FSEFOVDYSCIEIDRT PVVEIKOVLAAMRITNSOVIFPIVVVG MSEKTLIFYSLSTCGYCEITKKMLDDLEVDHKAIVVDLLTAEEKE KAVOELKKFNPNCTFPTLIYG MAEKRI IFYSISTCGHCEVTKKMIDDIDIFYHPIVVDIL PPDEKEKAVOEMTKSNPRCTFPTITYG MAEHSL IFYSLSTCGYCEVTKKLIDDLEVEYKAIVVDLLPADKKDVVIQELTKFNPRCTFPTLVHG MI HKNI TLYSLSTCI FCQA IKKMFDDLE ISFQCI QADELSKEEKKKAIKELKKVNPKCSFPTVVVD MAEKKI TLYSLTTCT FCQAVKKMLDDLDVT FECI QADEL PDKEKKEV IQELRKVNPQCSFPTVVID MTSONI IIYSLTTCGECSNIKKMLDDIKVS FTIIOADELDGDEKROVMKATRKVNDKCSFPTVVVG MAIKKI ILYSITTCVFCOAIKKMFDDIAATAHTCIOADEL SAEDKKKVLKDIRSVNPOCSFPTVVVD MTAKTVKLYGLSTCAYCOAIKKMLDDLGVAHDYVEADLLADAEREALVAELOAINPOCSFPTTVVG MENKKIKLYS ITTCAFCOAIKKMLKDLGVAYE FVDADLLFGGEREEMLEELRQVNPSCSFPTITID MQTKRIKLYSITTCAFCQAIKKMLTDLNVAHESVDADLLFGEEREALVSELRRINPSCSFPTIDID $::^{*}:::^{*} \ldots{ }^{*}:::::$ : $:$ : $^{*}$. : $^{*}{ }^{*}$. ETVVVGPKIQEIKEKIGIRTEVDELYEVLKKKNE PKGYYLNGDREKT FELIRGLITNKKRYGYMAC NQVIAGHNLQAIRDALGIRTE IAQLRDRLAVLAGKKGYCLNANREKTLRLLHALLLNRDRYGYMAC DKVI IGMKIOEIKDMI GVRTEVDDLYDTIRKIOE PKGYYFNRDKEKT FOLIRALIVNKDRYGYMSC FKVI IGIKPOETKDMIGVRTDVDKLEDTLRTOE PKGYYFNRDREKT FOLIRATLVNKDRYGYMSC DEVIVGYKVOEI KET I GIRTEVDDL FDMLKKSNE PKGYYLNGNKE KTYELILRSLIINKKRYGYMAC DAVIVGYKIQEIKET I GIRTEVDDLYDLLKKVNE PKGYFLNGNKEKT FELLRSLLTNKKRYGYMAC DEVVIGYKVQEIKEKIGIRTEVDELYDMLKKVNE PKGYYLNGNRE KT FELLRGLITNKKRYGYMAC GEVIVGYKVQEIKEK IGIHTEVDELYEMLRKINE PKGYYLNGDKE KT FELLRSLLTNKKRYGYMAC EQVIVGFQVQEIKEAIGIRTEVDELYDRLKTTQEAKGYW FNNDRERT FDLLRGLLINRDRYGYMSC GOTITGFKVOEIKEAIGIRTOVDELYDALKKIOE PKGYF FNRDKERDFDILRGLITNKDRYGYMSC GRIITGMKVQEIKET IGIRTKVDDLYDGLRKSQEARGYF FNQDKERT FELLRGLLTNKDRYGYMSC

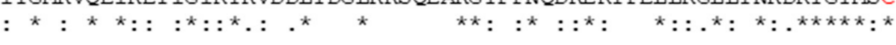

PCRIASGDRNNDRDI TCPCLYRE PDVKE FGSCYCTIYYVSADWYTGKTFROEVAERRPPEHYETD PCRAASGRRERDIDI ICPCIYRWADIAEYGSCYCGLYVAOEWDGVEL EOIHVPERRVVECO PCRLAAGERDKDKDI ICPCVYRE PDI KE FGSCYCNLYVSKAWNENTIEHTLVPERRSANHYP PCRLATGDREKDKDILCPCVYRE PDVRE FGSCYCNLYVSDEWNKGAIERHLVPERRSAEHYQ PCRLAAGDREKDKDIVCPCVYRE PDVQE FGSCYCNLYVSRDWNEGAIERHLVPERRSAEHYRKSSE PCRLASGTRDDDRDI ICPCVYRK PDI IEYGSCFCSLYVSAEWYTGKIERREVPERR PANLYDDE PCRLASGVRANDRDI ICPCTYRE PDIAEYGSC FCSLYVSADWYTAKIERKEVPERRPPELYEA PCRLGSGERDNDRDI ICPCTYRE PDVKE FGSCYCSLYVSADWYTGKIDRVEVPERRPPELYDFD PCRLASGVRENDRDI ICPCIYRE PDVAE FGSCFCSL YVSADWYTGKVKRQIVPERRPPEL YED PCRLAT GKREQDADI ICPCVYRQPDVAE FGACYCQL YVSEAWNRGAI PRL PVPERR PMRRG PCRLASGNRERDQDI ICPCVYREADVKE FGSCYCQLYVSAKWNEDIT PHAVVPERRVPNR PCRLAAGQREMDRDI ICPCVYRE PDVDE FGSCYCQLYVSRDWNDRKI PHVIVPERRPPQN

Figure 1. Redox active protein domains associated with a ferredoxin-disulfide reductase domain. (a) Represented here are natural fusion proteins containing a FTR/FDR domain associated with other 
protein domains both in the pfam (http:/ / pfam.xfam.org/ (accessed on 30 November 2021) and CDART (https://www.ncbi.nlm.nih.gov/Structure/lexington/lexington.cgi (accessed on 30 November 2021) databases. The average length of the amino acid sequences is indicated as well as the motifs containing known redox active cysteines. (b) Amino acid sequence alignment of GRX-FDR fusions. The sequence alignment was performed using Clustal Omega and * indicates the strictly conserved residues. The motifs containing redox active cysteines in GRX and FDR domains and Fe-S cluster cysteine ligands are in red. The GRX and FDR domains are delimited by the blue and green highlights, respectively. Abbreviations and corresponding accession numbers are as follows: DpGRX-FDR1: Desulfotalea psychrophila LSv54 (DP2155), DpGRX-FDR2: Desulfotalea psychrophila LSv54 (DP1729), Dsp5GRX-FDR: Desulfopila sp. IMCC35005 (2845940715), Dsp6GRX-FDR: Desulfopila sp. IMCC35006 (WP_136814623.1), Dsp8GRX-FDR: Desulfopila sp. IMCC35008 (WP_163339783.1), Dsb1GRX-FDR: Desulfobulbaceae bacterium (KAF0188140.1), Dsb2GRX-FDR: Desulfobulbaceae bacterium (PLX47268.1), DsaGRX-FDR: Desulfopila aestuarii (WP_073611837.1), DsfGRX-FDR: Desulfobulbus propionicus DSM 2032 (Despr_2150), DsbGRX-FDR: Desulfoprunum benzoelyticum DSM 28570 (2861205764), NtsGRXFDR1: Nitrospira bacterium SG8_35_1 (2656406240), NtsGRX-FDR2: Nitrospira bacterium SG8_35_1 (2656408917).

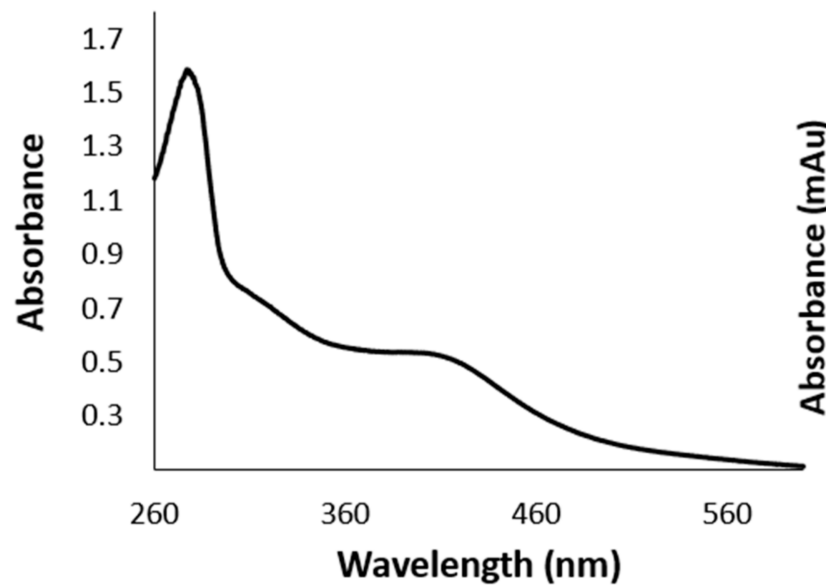

b

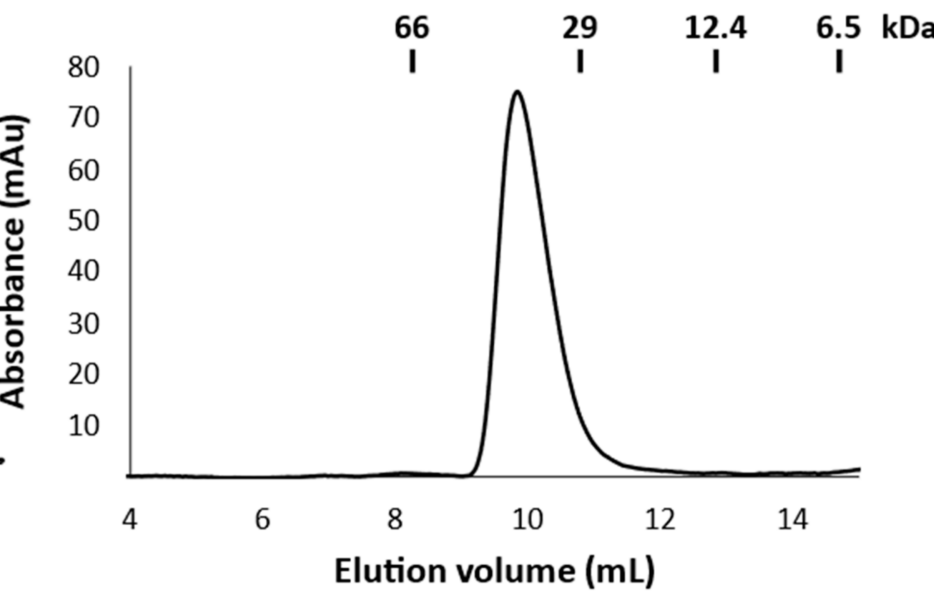

Figure 2. DpGRX-FDR1 is a dimeric Fe-S cluster containing protein. (a) UV-visible absorption spectrum of aerobically-purified DpGRX-FDR1. (b) Analytical gel filtration chromatogram of DpGRX-FDR1. One hundred micrograms of reduced DpGRX-FDR1 were loaded on a Sephadex S75 10/300 column connected to an ÄKTA purifier system and equilibrated in $30 \mathrm{mM}$ Tris- $\mathrm{HCl}$ pH 8.0. Protein absorbance was followed at $280 \mathrm{~nm}$. The apparent molecular weight of DpGRX-FDR1 was estimated from the separation of the indicated standards.

\subsection{Crystal Structure of DpGRX-FDR1}

The crystal structure of DpGRX-FDR1 was solved by selenomethionine singlewavelength anomalous dispersion at $2.1 \AA$ resolution (Table 1 ). The asymmetric unit contains a 2-fold dimer in a head-to-tail configuration. Each monomer consists of two functional domains, the N-terminal GRX-like domain being separated from the C-terminal FTR-like domain by a short linker of 4 residues. The comparison of both DpGRX-FDR1 subunits in the dimer revealed flexibility between the domains. Indeed, the superimposition of the subunits yields a rmsd value of $1.0 \AA$ whereas it does not exceed $0.35 \AA$ when the domains are superimposed separately (GRX-A GRX-B, $0.35 \AA$; FDR-A FDR-B, $0.20 \AA$ ). The latter rmsd values show that both FDR domains of the dimer (FDR-A and FDR-B) are extremely similar and that the same is true for both GRX domains (GRX-A and GRX-B). 
a

\section{Absorbance}

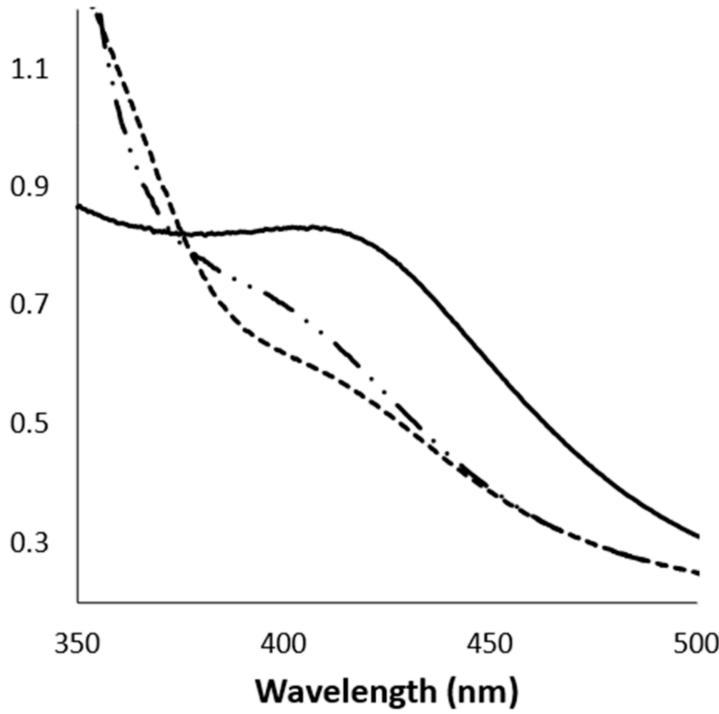

b

\section{Absorbance} at $340 \mathrm{~nm}$

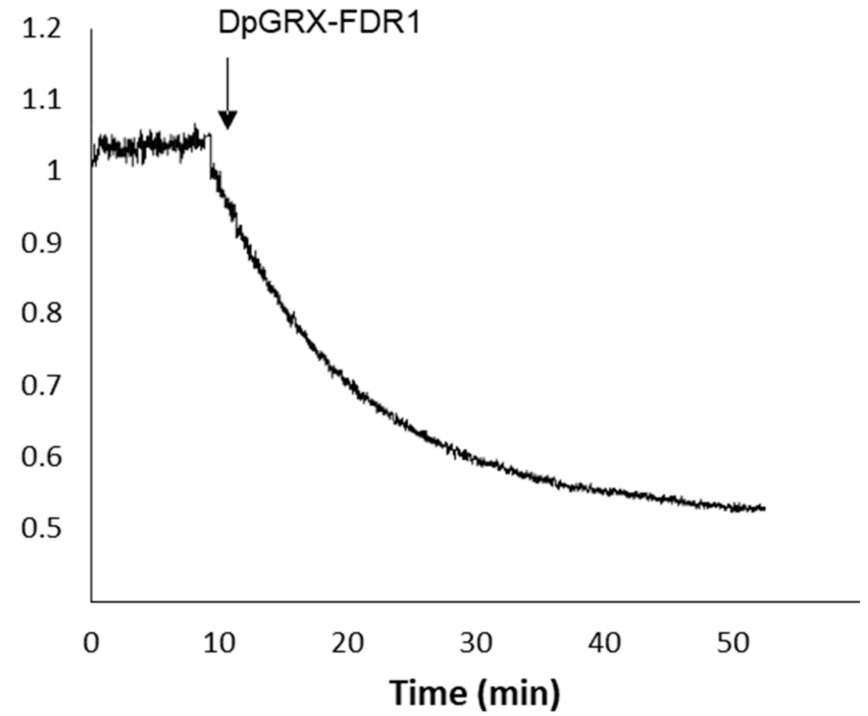

Figure 3. Reduction of the Fe-S cluster in DpGRX-FDR1. (a) Absorption spectrum in the 350-500 nm region of DpGRX-FDR1 either as purified protein (-) or reduced by dithionite (-“-) or by NADPH/FNR/FDX system (-). The concentration of DpGRX-FDR1 was $100 \mu \mathrm{M}$ in $30 \mathrm{mM}$ Tris $\mathrm{HCl}$ pH 8.0. (b) NADPH-coupled time-course reduction of DpGRX-FDR1 followed through the NADPH consumption at $340 \mathrm{~nm}$. A total of $140 \mu \mathrm{M}$ DpGRX-FDR1 was added after $10 \mathrm{~min}$ to a reaction medium containing $200 \mu \mathrm{M}$ NADPH, $0.75 \mu \mathrm{M}$ Chlamydomonas reinhardtii ferredoxin NADP+ reductase and $15 \mu \mathrm{M}$ SynFDX.

Table 1. Data collection and refinement statistics.

\begin{tabular}{|c|c|}
\hline Data Collection & Soleil Proxima 1 \\
\hline Space group & C2 \\
\hline $\begin{array}{l}\text { Cell constants } \\
a, b, c, \alpha, \beta, \gamma\end{array}$ & $\begin{array}{c}123.6 \AA 49.3 \AA 86.0 \AA \\
90.0^{\circ} 116.5^{\circ} 90.0^{\circ}\end{array}$ \\
\hline Resolution limits a $(\AA)$ & $41.42-2.08(2.13-2.08)$ \\
\hline Rmeas $^{\mathrm{a}, \mathrm{b}}(\%)$ & $3.7(23.4)$ \\
\hline $\mathrm{CC}_{1 / 2}(\%)^{\mathrm{a}, \mathrm{c}}$ & $99.9(97.2)$ \\
\hline Nr. of observations ${ }^{a, d}$ & $162,975(11,975)$ \\
\hline Nr. unique reflections ${ }^{a, d}$ & $54,222(3975)$ \\
\hline $\operatorname{Mean}((\mathrm{I}) / \mathrm{sd}(\mathrm{I}))^{\mathrm{a}, \mathrm{d}}$ & $23.0(5.9)$ \\
\hline Average redundancy ${ }^{\mathrm{a}, \mathrm{d}}(\%)$ & $98.7(97.8)$ \\
\hline Multiplicity ${ }^{\mathrm{a}}$ & $3.0(3.0)$ \\
\hline Mean anomalous difference ${ }^{a, e}$ & $1.42(0.82)$ \\
\hline \multicolumn{2}{|l|}{ Refinement } \\
\hline $\mathrm{R}_{\text {work }} / \mathrm{R}_{\text {free }}(\%)$ & $19.1 / 22.3(21.9 / 36.1)$ \\
\hline $\mathrm{Nr}$ test set reflections & $1353(4.8 \%)$ \\
\hline Atoms: protein, ligands, water & $3229,46,328$ \\
\hline
\end{tabular}


Table 1. Cont.

\begin{tabular}{cc}
\hline Data Collection & Soleil Proxima 1 \\
\hline B-wilson/B-average $\left(\AA^{2}\right)$ & $29 / 37$ \\
\hline r.m.s.d.bonds $(\AA) /$ angles $\left({ }^{\circ}\right)$ & $0.008 / 3.16$ \\
\hline Ramachandran: Fav./All. $(\%)$ & $99 / 1$ \\
\hline PDB ENTRY & $7 \mathrm{PWE}$ \\
\hline${ }^{\text {a }}$ Values in parentheses refer to the outer resolution shell; ${ }^{\mathrm{b}} R_{\text {meas }}=\sum_{h k l} \sqrt{\frac{n}{n-1}} \sum_{i=1}^{n}\left|I_{i}(h k l)-\bar{I}(h k l)\right| / \sum_{h k l} \sum_{i=1}^{n}$ \\
$I_{i}(h k l) ;{ }^{c}$ Percentage of correlation between intensities from random half-datasets; ${ }^{\mathrm{d}}$ Friedel pairs were treated \\
as different reflections during the scaling and merging procedure; ${ }^{\mathrm{e}}$ Mean anomalous difference in units of its \\
estimated standard deviation $(|\mathrm{F}(+)-\mathrm{F}(-)| /$ Sigma).
\end{tabular}

In the dimer, the N-terminal domain of one monomer interacts mainly with the Cterminal domain of the other monomer (Figure 4). This interaction is similar to the one described for Synechocystis FTR with spinach TRX-f or TRX-m ([5] see below). Thus, the DpGRX-FDR1 dimer can be described as two GRX-FDR heterocomplexes. In the following sections, the GRX-FDR heterocomplex that will be detailed is the one between the FDR domain of monomer A (DpFDR) and the GRX domain of monomer B (DpGRX).

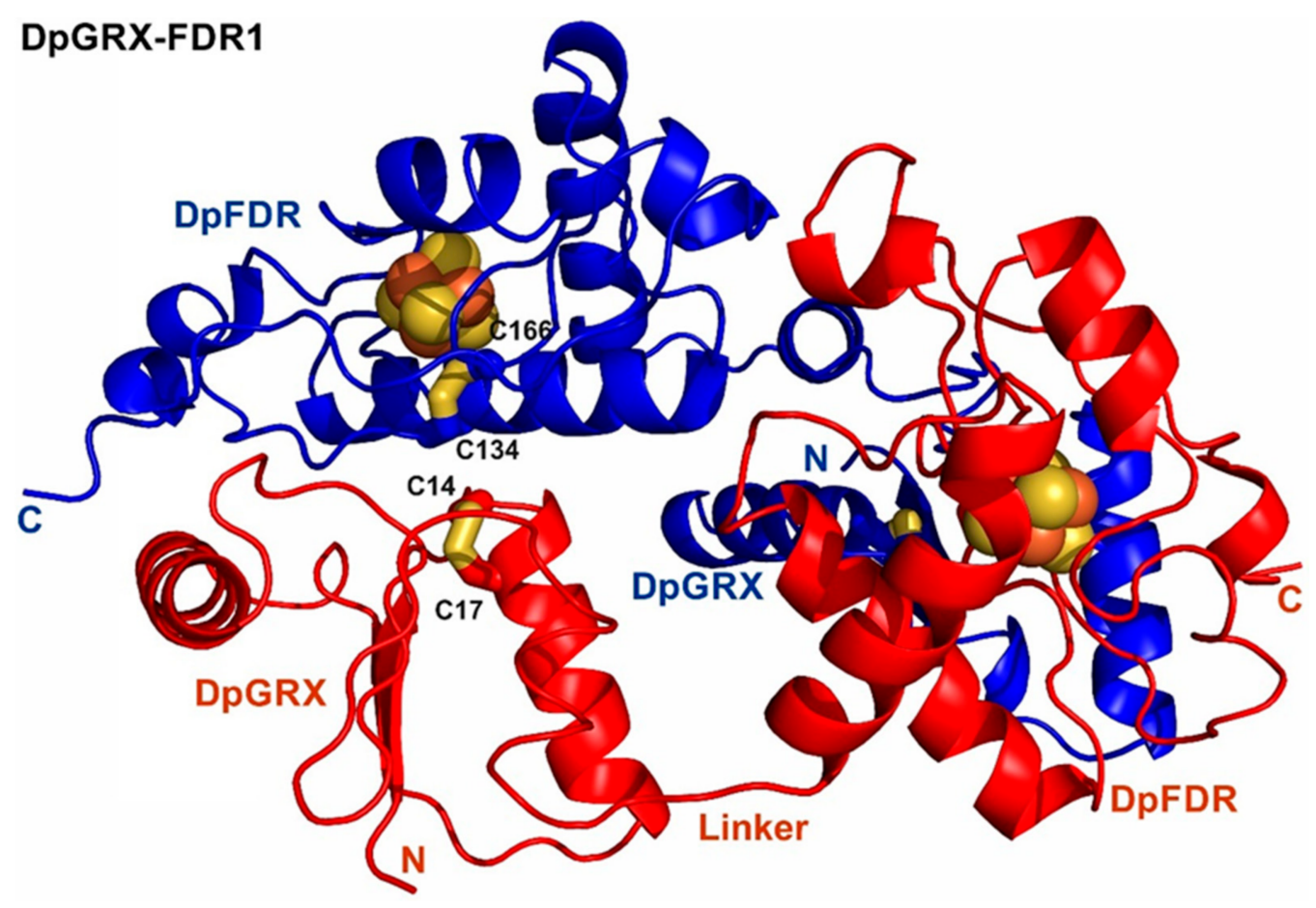

Figure 4. X-ray crystal structure of the DpGRX-FDR1 dimer. In each subunit, the figure highlights the disulfide bridge C14-C17 in the N-terminal GRX domain, and the [4Fe-4S] cluster and the disulfide bridge C134-C166 in the C-terminal FDR domain. The polypeptide chains are shown as cartoon ribbons, the disulfide bridges as sticks and the [4Fe-4S] clusters as CPK spheres.

The GRX-like domain of DpGRX-FDR1 (DpGRX) adopts a thioredoxin fold ( $\beta 1 \alpha 1 \beta 2$ $\alpha 2 \beta 3 \beta 4 \alpha 3$ ) without additional $N$ - or C-terminal $\alpha$-helices unlike most GRXs [20]. The cysteines of the $\mathrm{C}_{14} \mathrm{GFC}_{17}$ signature are located at the $\mathrm{N}$-terminus of $\alpha 1$ helix and form an intramolecular disulfide bridge. DpGRX contains a cis-proline (P61) at the N-terminus of $\beta 3$ strand, which is a topologically conserved residue in most members of the TRX superfamily [21]. The disulfide bridge C14-C17 is close to the [4Fe-4S] center of the FDR domain of the other monomer (DpFDR) and more particularly to C134 residue. Interestingly, the distance between the $\mathrm{C} \alpha$ atoms of $\mathrm{C} 14$ and $\mathrm{C} 134$ is equivalent to the distance found in the FTR-TRX heterocomplex (5.0 $\AA$ and $4.8 \AA$, respectively) [4]. A search for structural 
homologs using Dali [22] or PDBeFold [23] ranked the methanoredoxin from $M$. acetivorans (MaMRX) at the top of the list (33\% sequence identity) [13]. The other hits were a homolog of MaMRX from M. mazei, a TRX-like protein [24], a GRX from Archaeoglobus fulgidus and two bacterial $\mathrm{NrdH}[25,26]$. Figure S2 shows a sequence alignment based on these models and those of spinach TRX-f and $-\mathrm{m}$. All the proteins possess the CXXC motif and the cis-proline. DpGRX does not contain the NrdH-specific WSGFRP(D/E) motif located in the $\beta 4 \alpha 3$ loop [26]. Figure S2 also highlights the residues of DpGRX in contact with DpFDR, which are located at the same positions as those present in both spinach TRXs in FTR-TRX heterocomplexes.

The FDR domain of DpGRX-FDR1 (DpFDR) has an overall $\alpha$-helical structure $\left(\alpha 1^{\prime} \alpha 2^{\prime}\right.$ $\left.\alpha 3^{\prime} \alpha 4^{\prime} \alpha 5^{\prime}\right)$ and contains a [4Fe-4S] cluster. It bears the catalytic fingerprint $\mathrm{CPC} \mathrm{x}_{14} \mathrm{CPC} \mathrm{x}_{12} \mathrm{CYC}$ that corresponds to the previously defined group VI of the FTR superfamily (Figure S3) [9]. The Fe-S cluster is coordinated by the first (C132), third (C149), fourth (C151) and fifth (C164) cysteine residues of the fingerprint while the two other cysteine residues (C134 and C166) form a disulfide bridge (Figure 5). This configuration is characteristic of the oxidized $[4 \mathrm{Fe}-4 \mathrm{~S}]^{2+}$ resting state of FTR [5]. The other groups close to the cluster are mostly aliphatic except for the guanidinium group of R134, which is hydrogen bonded to one sulfide ion.

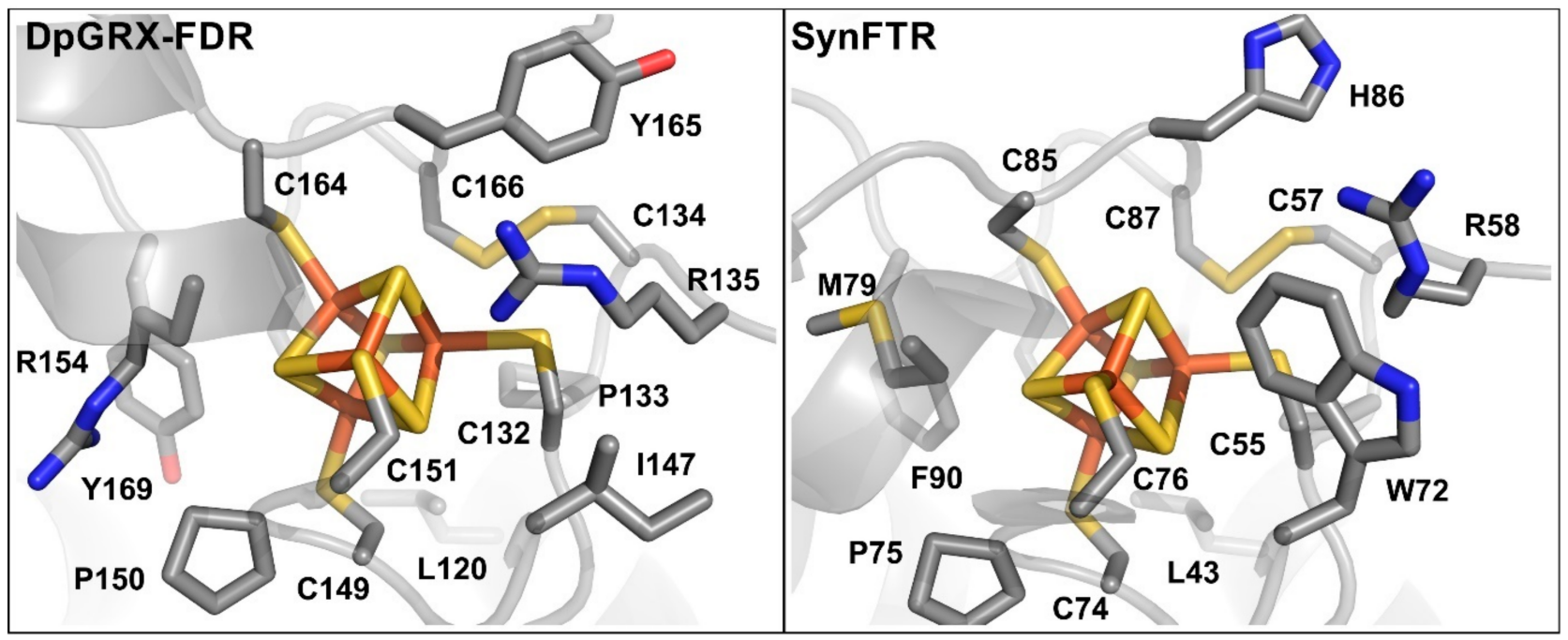

Figure 5. Comparison of the environment of the [4Fe-4S] cluster in DpGRX-FDR1 (left) and in Synechocystis FTRc (right). The residues and the clusters are shown as sticks and the residues are labelled.

The closest homolog of DpGRX-FDR1 in the PDB is the M. acetivorans FDR2 (MaFDR2), which is also a multi-domain protein. It contains an N-terminal FDR domain and a C-terminal RBX domain [11]. Its quaternary structure is also a dimer in a head-to-tail configuration in which the FDR domain of one monomer interacts mainly with the RBX domain of the other monomer. Thus, the MaFDR2 dimer can be described as two RBXFDR heterocomplexes. The RBX domain was proposed to mediate electron transfer from ferredoxin to the Fe-S center of the FDR domain [11] but FDX-dependent reduction still occurs in its absence [12]. MaFDR2 belongs to the group VI of the FTR superfamily as DpGRX-FDR1 [9]. The FDR domains of MaFDR2 and DpGRX-FDR1 share nearly identical structures. Their superimposition shows an rmsd of $0.63 \AA$ ( 83 aligned residue pairs) and $48 \%$ sequence identity (Figure S3). They share the same catalytic fingerprint with a tyrosine residue as central residue of the third $\mathrm{CxC}$ motif. The first neighboring residues of the [4Fe-4S] cluster are identical in both MaFDR2 and DpGRX-FDR1, including the arginine residue (R135 in DpFDR-FDR1 and R53 in MaFDR2) described above (Figure 5).

By comparing the DpFDR domain to SynFTRc, two major differences were noticed although the overall fold is similar. Exclusively aliphatic groups surround the Fe-S cluster of SynFTRc. In the DpFDR domain, the guanidinium group of R135 is hydrogen bonded to 
a sulfide ion. In fact, the side chain of the corresponding arginine residue in SynFTRc (R58) is away from the Fe-S center. In DpFDR, R135 cannot occupy the equivalent space since the side chain of Y165 partially fills it. This tyrosine residue is the central residue of the third CxC motif of DpFDR and is replaced by the H86 residue in SynFTRc. Interestingly, this histidine residue is supposed to increase the redox potential of the Fe-S cluster [5]. The second difference concerns the C-terminal ends of DpFDR and SynFTRc that occupy distinct regions. The fifth helix in SynFTRc packs along the two first helices and together forms a cap at the top the Fe-S center (Figure 6) [4]. This helix cannot occupy the same position in DpGRX-FDR1 due to the N-terminal GRX domain. In DpFDR, the C-terminal tail next to the last $\mathrm{CxC}$ motif contains a short helix $\left(\alpha 5^{\prime}\right)$ and a long loop that covers the bottom of the Fe-S center (Figure 6). This loop contains the motif $\mathrm{E}_{186} \mathrm{RRP}_{189}$ and the side chain of the glutamate residue forms a salt bridge with R135, located in the first shell of the Fe-S cluster (see above). In SynFTR heterodimer, the equivalent region is covered by residues of the variable subunit (FTRv), which are believed to shield the Fe-S cluster of the FTRc subunit (Figure 6) [4]. Hence, we propose that the C-terminal loop present in the FDR domain of DpGRX-FDR1 replaces the FTRv subunit in protecting and/or stabilizing the [4Fe-4S] cluster.

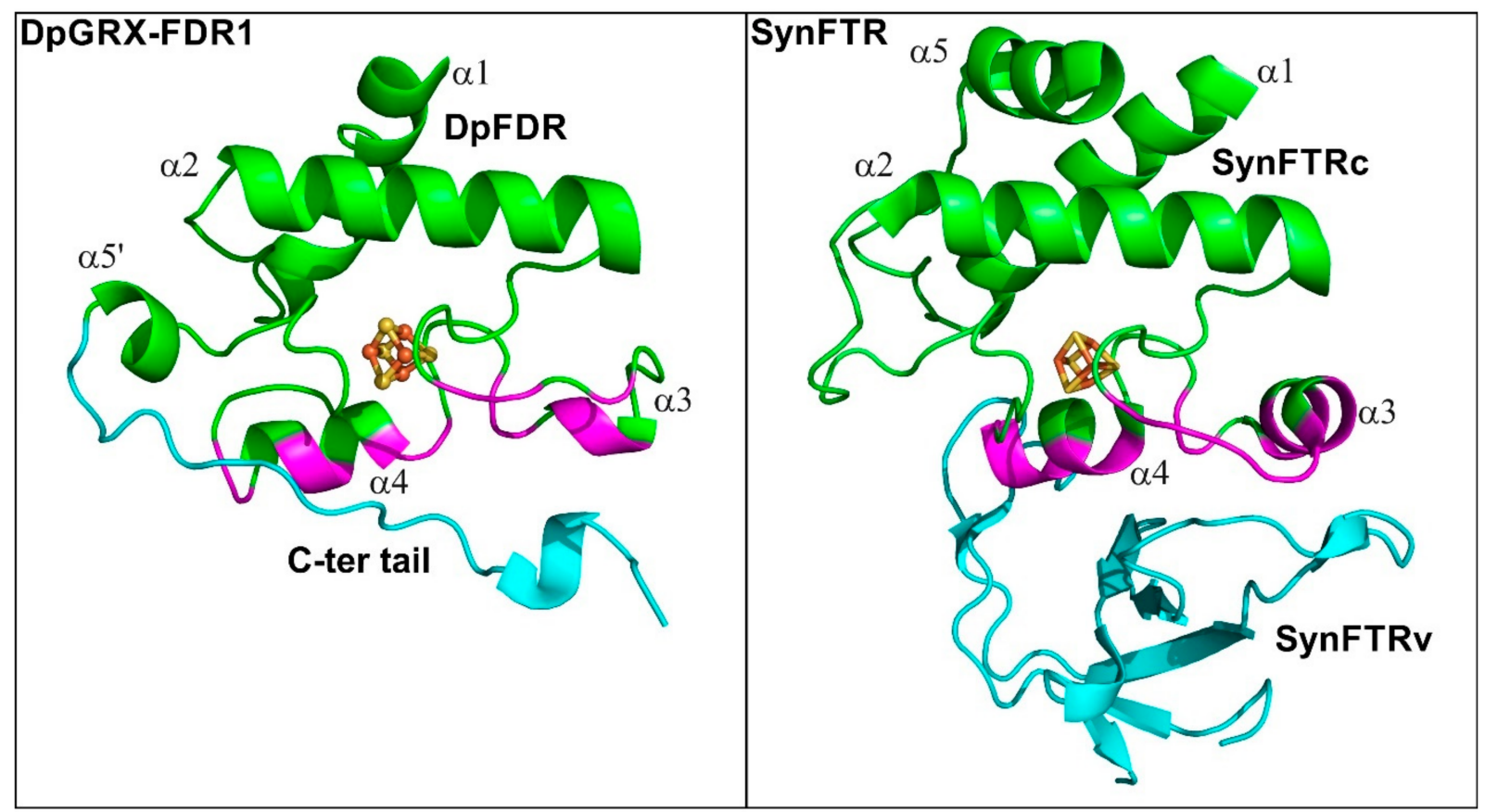

Figure 6. Comparison of the Dp-FDR domain (left) and the Synechocystis FTR heterodimer (right). The figure highlights that the C-terminal tail of Dp-FDR shields the Fe-S cluster in the same way as the FTRv chain in SynFTR heterodimer. The regions in contact with the C-terminal tail in Dp-FDR or with the FTRv chain are indicated in magenta. The polypeptide chains are shown as cartoon ribbons and the $[4 \mathrm{Fe}-4 \mathrm{~S}]$ clusters as balls and sticks.

\section{Discussion}

Several electron donor sources were reported for thioredoxin reductases: primarily $\mathrm{NAD}(\mathrm{P}) \mathrm{H}$ and ferredoxin, but also rubredoxin [11], coenzyme $\mathrm{F}_{420}$ [27] or else a hydrogenase in the hyperthermophilic archaeon Thermococcus onnurineus NA1, the electrons deriving from $\mathrm{H}_{2}$ oxidation [28]. In plants, FTR receives electrons from [2Fe-2S]-containing FDXs and delivers them to all conventional chloroplastic TRXs, belonging to the TRX $\mathrm{m}, \mathrm{f}, \mathrm{x}, \mathrm{y}$ and $z$ types although with different efficiencies [2,17,29]. In contrast, the Methanosarcina barkeri FDR1 is unable to reduce the TRXA or methanoredoxin and seems specific to NrdH itself being involved in the reduction of class III RNR [10]. In fact, $\mathrm{NrdH}$ is not reduced by the NADPH-thioredoxin reductase [10]. In M. acetivorans, which contains 7 TRX proteins, 
FDR2 only reduces TRX5 and MRX using FDX as the reductant but not other TRXs whose reducing systems remain unknown [30]. Only TRX7 was shown to be reduced by the sole NADPH-thioredoxin reductase present in this organism [30]. MaFDR2 is reduced by FDX via its RBX domain, even though a variant devoid of this domain retains its ferredoxindependent activity indicating that this FDR domain conserved the capacity to interact with FDX [11]. All of this information raises questions regarding the type of both the electron donors and acceptors for FTR/FDR family members. Combining biochemical and structural analyses should provide clues about these specificities. However, while FTR/FDR family members are widespread, being present in archaea, bacteria and photosynthetic eukaryotes, only a few 3D structures have been solved thus far. Resolution of the structure of Arabidopsis and Synechocystis FTRs which form heterocomplexes between a catalytic and a variable subunit [4,29], alone or in complex with FDX and TRX have provided details for both the catalytic mechanism and interaction specificities, but FTR and FDR differ substantially in their structural organization $[4,5,29]$. On the FDR side, only an RBX-FDR fusion from $M$. acetivorans was structurally characterized thus far which provided details about the interaction of FDR with the RBX electron donor [11]. In this study, we provided details on the interaction of FDR with its electron acceptor, here a GRX-like protein.

MaFDR2 and DpGRX-FDR1 are two multi-domain homodimeric proteins in which both domains possess catalytic functions. Moreover, the structural organization implies that electrons are not exchanged within a monomer but between domains of each monomer. On the contrary, plant FTRs are heterodimers in which the variable subunit has no catalytic function, but a suggested protective role for the Fe-S cluster [4]. The biochemical studies performed on MaFDR2 indicated that the RBX domain does not bear such protective or stabilizing effects since a protein devoid of this domain is equally well stable and active [12]. In fact, we have observed a C-terminal tail specific to FDR domains in DpGRX-FDR1 and MaFDR2 that could play the role of the FTRv subunit in protecting the cluster from oxygen. Accordingly, DpGRX-FDR1 can be purified with its cluster intact under aerobiosis. A conserved ERR[P/V/S] motif in FDRs appears important since it interacts with the residues of the first shell of the Fe-S cluster (Figure 1b).

In this study, we observed that DpGRX-FDR1 was reduced by a plant-type FDX. However, there is apparently no such FDX encoded by the genome of D. psychrophila since we have only identified one gene coding for a FDX putatively incorporating a [4Fe-4S] cluster as shown for other FDXs present in sulfate-reducing bacteria [31]. Several genes coding for proteins containing a RBX domain exist in this bacterium. Only one corresponds to a protein with a single RBX domain (DP2913). In other cases, it is associated with other protein domains, one annotated as rubrerythrin (DP1656) and one corresponding to a membrane domain (DP1260). The percentages of sequence identity of these DpRBX domains with the RBX domain of MaFDR2 range from $30 \%$ to $40 \%$. We predicted the three dimensional structure of DP2913 (single RBX domain) using ColabFold [32] to propose a ternary complex DpRBX/DpFDR/DpGRX (Figure 7). The built complex appears to be competent as the spacing between the redox centers of the three proteins (RBX, FDR, and GRX) is close to that observed in the ternary complex FDX/FTR/TRX. Moreover, the three redox centers are aligned. It was proposed that this alignment is necessary to maximize the efficiency of electron transfer from the FDX [2Fe-2S] cluster to the TRX active site disulfide in the FTR system [5]. While this gives credence to the possibility that RBX from D. psychrophila can serve for relaying electrons, the question of the electron source remains. It is possible that the FDX identified in D. psychrophila play this role since a [4Fe-4S]-containing FDX from $M$. acetivorans proved to be active with MaFDR2 [11]. Another possibility is that reduction is performed by one of the numerous flavin-dependent oxidoreductases encoded by the D. psychrophila genome. 


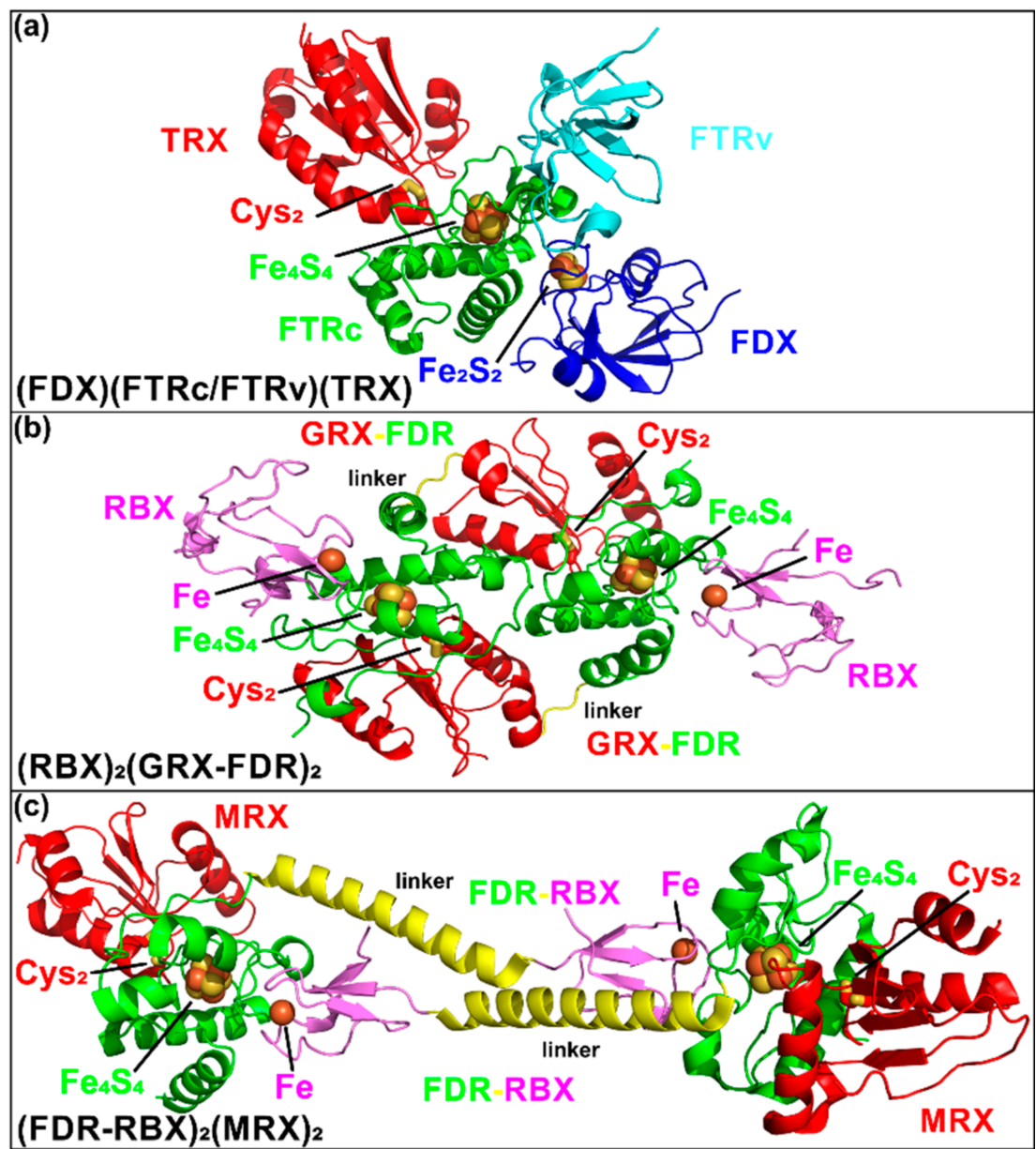

Figure 7. Overall structure of the plant FDX-FTR-TRX-f complex (a) and proposed ternary complexes RBX-FDR-GRX in D. psychrophile (b) and RBX-FDR-MRX in M. acetivorans (c). All proposed ternary complexes are dimers of ternary complexes. In (a), the crystal structure of the plant FDX-FTR-TRX-f is presented (PDB ID 2pvo) [5]. In (b), DpFDR and MaFDR protomers were superimposed to propose a position of the rubredoxin protein in the D. psychrophila RBX-GRX-FDR complex. The model structure of the D. psychrophila RBX protein (GenBanK ID CAG37642) was generated using ColabFold [32]. In (c) DpFDR and MaFDR protomers were superimposed to propose a position of the methanoredoxin enzyme in M. acetivorans RBX-FDR-MRX complex. The crystal structure of MRX from M. acetivorans (PDB ID 5cax) was used in the RBX-FDR-MRX complex. In all figures, the [2Fe-2S] cluster (or Fe atom) of FDX (or RBX), the [4Fe-4S] cluster of FTR (or FDR) and the active-site cysteines of TRX (or GRX or MRX) are shown to highlight the alignment of the redox centers in the ternary complexes. The polypeptide chains are shown as cartoon ribbons, the cysteine side chains as sticks and the iron atoms and clusters as CPK spheres.

Regarding the electron acceptor, the comparison of the FTR-TRX heterocomplex and the DpGRX-FDR1 homodimer shows that the mode of assembly is globally similar. However, when superimposing SynFTRc with the DpFDR domain, the TRX and GRX domains do not overlap perfectly. The best overlapping regions are the active sites. This comparison shows that in the DpGRX-FDR1 dimer, the FDR domain of one subunit is in the adequate position to reduce the disulfide bridge of the GRX domain of the other monomer. In $M$. acetivorans, the MaFDR2 gene is adjacent to a gene coding for a methanoredoxin (MaMRX). Accordingly, MaFDR2 reduces MaMRX [12]. This MaMRX displays a structure close to the DpGRX domain (rmsd of $1.0 \AA$ for 74 aligned residue pairs). From the DpGRXFDR1 structure, it is possible to propose with confidence a model of MaFDR2 in complex with MRX which actually corresponds to two ternary RBX/FDR/MRX complexes (Figure 7). This modeling would not have been possible from the plant FTRc-TRX heterocomplexes 
since the structures of chloroplastic TRXs and MRX are significantly different (rmsd of $6.3 \AA$ for 60 aligned residue pairs).

An interesting observation was that the GRX-like domain of DpGRX-FDR1 binds a [2Fe-2S] cluster when expressed alone whereas this is hampered in the context of the fusion protein due to the position of the cysteine residues. According to the propensity of several mono-domain GRXs to bind this type of cluster and the known requirement for residues interspacing the CxxC motif in GRXs, this is not so surprising. Indeed, DpGRXFDR1 possesses a CGFC signature that is extremely similar to the one present in so-called monothiol GRXs (CGFS signatures) that bind labile Fe-S clusters [18,19]. In contrast, Fe-S cluster binding was not described for MaMRX despite exhibiting a fold similar to GRXs [13]. The reason may be that the cluster is too labile to be observed or isolated, or more likely that the CVWC active site signature is not adapted.

In conclusion, these structural data provide additional clues about the similarities and differences among members of the FTR/FDR family. While a non-catalytic variable subunit is thought to shield the Fe-S cluster from degradative oxidation in photosynthetic FTRs, archaeal and bacterial FDRs instead bear a protective C-terminal tail. Moreover, taking advantage of the second chimeric FDR structure available with RBX and FDR domains, we were able to propose a robust model for a tripartite complex with FDR associated with its electron donor, rubredoxin, and its electron acceptor, glutaredoxin-like/methanoredoxin, thus reconstituting the whole electron transfer pathway (Figure 8). This highlights another difference which is the direct dependence of FTRs towards FDXs, whereas an RBX relay exists for FDRs even though FDRs are able to accept electrons directly from FDX as well.

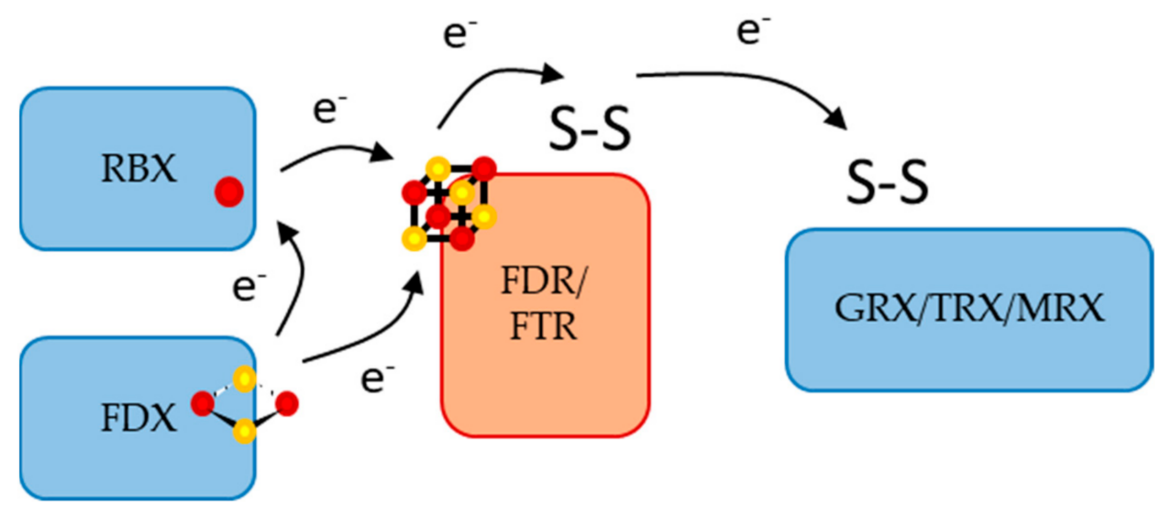

Figure 8. Electron transfer pathways involving ferredoxin-thioredoxin reductase (FTR) or ferredoxindisulfide reductase (FDR). In photosynthetic organisms, FTR receives electrons directly from the [2Fe-2S] cluster of ferredoxin (FDX). In non-photosynthetic organisms, FDR receives electrons either directly from the Fe-S cluster of FDX or via a relay by the Fe center of rubredoxin. Then, electrons received by the $[4 \mathrm{Fe}-4 \mathrm{~S}]$ cluster present in FTR or FDR are used to reduce a disulfide bond on these proteins before the newly reduced cysteines react in turn with disulfide bonds present in the electron acceptor, whether it is a glutaredoxin (GRX)-, thioredoxin (TRX)- or methanoredoxin (MRX)-type protein.

\section{Materials and Methods}

\subsection{PCR Cloning}

The sequence encoding D. psychrophila Lsv54 GRX-FDR1 (DP2155) was synthesized by the Genecust Company (Luxembourg) integrated in a pUC58 plasmid and subcloned into the pET12a plasmid between NdeI and BamHI restriction sites using primers listed in Table S1. The respective GRX and FDR domains were also cloned independently between the NdeI and BamHI restriction sites of a pET15b plasmid using primers listed in Table S1, in order to introduce an $\mathrm{N}$-terminal His tag. 


\subsection{Expression in E. coli and Purification of the Recombinant Proteins}

The E. coli BL21(DE3) strain, containing the pSBET plasmid, which expresses the tRNA recognizing the AGG and AGA codons, was used for protein expression. Cultures were successively amplified up to $2.4 \mathrm{~L}$ in LB medium supplemented with ampicillin and kanamycin $(50 \mu \mathrm{g} / \mathrm{mL})$ at $37^{\circ} \mathrm{C}$. Protein expression was induced at exponential phase by adding $100 \mu \mathrm{M}$ isopropyl $\beta$-D-thiogalactopyranoside for $4 \mathrm{~h}$ at $37^{\circ} \mathrm{C}$. The cultures were then centrifuged for $15 \mathrm{~min}$ at $4400 \times \mathrm{g}$. The pellets were resuspended in $30 \mathrm{~mL}$ of Tris $\mathrm{NaCl}$ (30 mM Tris- $\mathrm{HCl} \mathrm{pH} \mathrm{8.0,} 200 \mathrm{mM} \mathrm{NaCl}$ ) buffer, and the cells were stored at $-20^{\circ} \mathrm{C}$.

For the production of selenomethionine-labeled protein, the BL21(DE3) Met- strain, auxotroph for methionine, was used. Bacteria from a starter culture of $10 \mathrm{~mL}$ in rich medium (LB) served to inoculate an M9 minimal medium supplemented with all amino acids at $40 \mathrm{mg} / \mathrm{L}$ except methionine. Once the $2 \mathrm{~L}$ culture reached the exponential phase, the production of the recombinant protein was induced by adding $100 \mu \mathrm{M}$ isopropyl $\beta$-Dthiogalactopyranoside for $5 \mathrm{~h}$ at $37^{\circ} \mathrm{C}$ and the medium was supplemented with $40 \mathrm{mg} / \mathrm{L}$ of selenomethionine and $20 \mu \mathrm{M}$ of $\mathrm{FeCl}_{3}$.

For purification, cell lysis was performed by sonication $(3 \times 1 \mathrm{~min}$ with intervals of $1 \mathrm{~min}$ ) and the soluble and insoluble fractions were separated by centrifugation for $30 \mathrm{~min}$ at $27,000 \times g$. The soluble portion was then fractionated with ammonium sulfate in two steps, and the protein fraction precipitating between $20 \%$ and $80 \%$ of the saturation contained the recombinant protein as estimated by $15 \%$ SDS-PAGE. Both labelled and unlabeled proteins were purified by size exclusion chromatography (ACA44 column, $5 \times 75 \mathrm{~cm}$ ) in Tris $\mathrm{NaCl}$ buffer. The fractions containing the protein were pooled, dialyzed by ultrafiltration to remove $\mathrm{NaCl}$ and loaded onto a DEAE (diethylaminoethyl) cellulose column (Sigma, St. Louis, MO, USA) equilibrated in a $30 \mathrm{mM}$ Tris- $\mathrm{HCl} \mathrm{pH} 8.0$ buffer. The recombinant proteins were eluted using a 0 to $0.4 \mathrm{M} \mathrm{NaCl}$ gradient. The fractions of interest were concentrated by ultrafiltration under nitrogen pressure (Amicon, YM10 membrane) and stored in the same buffer at $-20^{\circ} \mathrm{C}$.

For His-tagged proteins, the cell pellets were resuspended in $20 \mathrm{~mL}$ of a $30 \mathrm{mM}$ Tris$\mathrm{HCl} \mathrm{pH}$ 8.0, $10 \mathrm{mM}$ imidazole, $300 \mathrm{mM} \mathrm{NaCl}$ buffer, and the cells eventually stored at $-20{ }^{\circ} \mathrm{C}$. The GRX domain was purified from the soluble fraction using an IMAC-Select affinity gel column (Sigma Aldrich, St. Louis, MO, USA) equilibrated in the same buffer under anaerobic conditions (Jacomex glove box). After extensive washing, the recombinant protein was eluted using the same buffer except with an imidazole concentration of $250 \mathrm{mM}$. The protein was concentrated using a $10 \mathrm{kDa}$ cut-off "centricon" filter and stored in the same buffer at $-20^{\circ} \mathrm{C}$.

Protein purity was assessed by SDS-PAGE and protein concentrations were determined spectrophotometrically using a molar extinction coefficient at $280 \mathrm{~nm}$ of $22,515 \mathrm{M}^{-1} \mathrm{~cm}^{-1}$ for DpGRX-FDR1 and $1490 \mathrm{M}^{-1} \mathrm{~cm}^{-1}$ for DpGRX.

The oligomerization state of a DTT-reduced DpGRX-FDR1 was analyzed on a Sephadex75 10-300 column linked to an ÄKTA Purifier system (GE Healthcare, Logan, UT, USA) equilibrated in a $30 \mathrm{mM}$ Tris- $\mathrm{HCl} \mathrm{pH} \mathrm{8.0,} \mathrm{by} \mathrm{loading} 100 \mu \mathrm{g}$ of a freshly anaerobicallypurified protein at a flow rate $0.5 \mathrm{~mL} \mathrm{~min}^{-1}$. Detection was recorded at $280 \mathrm{~nm}$. The column was calibrated using the following molecular weight standards: bovine serum albumin $(66 \mathrm{kDa}, 8.9 \mathrm{~mL})$, carbonic anhydrase $(29 \mathrm{kDa}, 11.3 \mathrm{~mL})$, cytochrome c (12.4 kDa, $13.4 \mathrm{~mL})$ and aprotinin $(6.5 \mathrm{kDa}, 15.6 \mathrm{~mL})$.

\subsection{Quantification of Iron and Acid-Labile Sulfide Bound to Proteins}

For iron quantification, different amounts of protein $(2,4,6,8$ and $10 \mathrm{nmol})$ were diluted in $130 \mu \mathrm{L}$ water. A $90 \mu \mathrm{L}$ volume of $70 \%(v / v)$ perchloric acid was added for protein denaturation and precipitation. The mixture was vortexed $5 \mathrm{~min}$, incubated for $15 \mathrm{~min}$ at room temperature and then centrifuged $(5 \mathrm{~min}$ and $11,600 \times \mathrm{g}$ ) to remove precipitated proteins. A $180 \mu \mathrm{L}$ volume of supernatant was mixed with $144 \mu \mathrm{L}$ of the iron chelator bathophenanthroline disulfate at $1.7 \mathrm{mg} \mathrm{mL}^{-1}$, with $72 \mu \mathrm{L}$ sodium ascorbate at $32 \mathrm{mg} \mathrm{mL}^{-1}$ for the reduction of ferric to ferrous iron and with $152 \mu \mathrm{L}$ ammonium acetate 
at $477 \mathrm{mg} \mathrm{mL}^{-1}$. The final mixture was vortexed $5 \mathrm{~min}$ and incubated for $30 \mathrm{~min}$ at room temperature. The specific absorbance of the ferrous iron-chelator complex was measured at $535 \mathrm{~nm}$ whereas the non-specific absorbance at $680 \mathrm{~nm}$ was subtracted. Standard curve was obtained using 0 to $150 \mu \mathrm{M}$ ammonium iron(II) sulfate solution obtained by dilution from a $10 \mathrm{mM}$ stock solution prepared in $1 \mathrm{~N} \mathrm{HCl}$.

For sulfide quantification, 0 to $10 \mathrm{nmol}$ proteins were dissolved in $100 \mu \mathrm{L}$ degassed water and mixed with $300 \mu \mathrm{L}$ of $1 \%(w / v)$ zinc acetate at $10 \mathrm{mg} \mathrm{mL}^{-1}$ and $15 \mu \mathrm{L} \mathrm{NaOH}$ $3 \mathrm{M}$. After $5 \mathrm{~min}$ vortexing and $10 \mathrm{~min}$ incubation at room temperature, $50 \mu \mathrm{L}$ of $0.01 \%$ $(w / v) N, N$-Dimethyl-p-phenylenediamine (dissolved in $\mathrm{HCl} 5 \mathrm{M}$ ) and $50 \mu \mathrm{L}$ of $23 \mathrm{mM}$ iron chloride $\mathrm{FeCl}_{3}$ (dissolved in $\mathrm{HCl} 1.2 \mathrm{M}$ ) were added. After 5 min vortexing and $3 \mathrm{~h}$ incubation at $4{ }^{\circ} \mathrm{C}$, the mixture was centrifuged $(5 \mathrm{~min}, 11,600 \times \mathrm{g})$ and the formation of methylene blue was measured by recording absorbance at $670 \mathrm{~nm}$. Standard curve was obtained using 0 to $100 \mu \mathrm{M}$ lithium sulfide solution obtained by dilution from a $20 \mathrm{mM}$ stock solution prepared in $0.3 \mathrm{~N} \mathrm{NaOH}$.

\subsection{Reduction of DpGRX-FDR1}

Two alternative methods were used. First, a solution of $100 \mu \mathrm{M}$ DpGRX-FDR1 was reduced under anaerobic conditions by adding $1 \mathrm{mM}$ dithionite. In a second experiment, $140 \mu \mathrm{M}$ DpGRX-FDR1 was incubated anaerobically with a coupled system including a NADPH $(200 \mu \mathrm{M})$, Chlamydomonas reinhardtii ferredoxin NADP+ reductase $(0.75 \mu \mathrm{M})$ and SynFDX $(15 \mu \mathrm{M})$. The changes in the UV-visible absorption spectrum were followed over time using a Cary 60 spectrophotometer until no variation occurred and the results are shown in Figure 3a. Reduction was also followed by recording NADPH oxidation over time using the same reaction as above.

\subsection{Crystallography}

The selenomethionylated form of DpGRX-FDR1 was crystallized using the microbatch under oil method at $4{ }^{\circ} \mathrm{C}$. The protein $\left(7 \mathrm{mg} \mathrm{mL}^{-1}\right.$ in $30 \mathrm{mM}$ Tris- $\mathrm{HCl} \mathrm{pH} \mathrm{8.0)}$ was crystallized by mixing $1 \mu \mathrm{L}$ of protein solution and $1 \mu \mathrm{L}$ of crystallization solution (JBScreen Classic condition JBS6 B2 containing a mixture of 30\% MPD, 10\% PEG4000, and 0.1 M imidazole-HCl pH 8; Jena Bioscience, Inc., Jena, Germany). Single crystals were flash-cooled in liquid nitrogen using a mixture of the crystallization condition and $20 \%$ glycerol as cryoprotectant. A synchrotron data set (beamline PROXIMA-1, SOLEIL, St. Aubin, France) was collected at $100 \mathrm{~K}$ to $2.10 \AA$ resolution at the selenium peak $(0.97911 \AA)$. The data were processed with XDS [33]. The structure was determined by the Se single-wavelength anomalous dispersion (SAD) phasing method. Preliminary phases were determined using Autosol procedure of PHENIX [34] and the partial results were enhanced by Buccaner [35]. The initial model was refined with Buster [36] and rebuilt iteratively using Coot [37]. Crystallographic parameters, data-collection statistics and refinement statistics are listed in Table 1.

\subsection{Sequence Analysis and 3D Structure Modelling}

Protein domain analysis was performed by interrogating the pfam (http://pfam. xfam.org/, accessed on 30 November 2021) and CDART (https: / /www.ncbi.nlm.nih.gov / Structure/lexington/lexington.cgi, accessed on 30 November 2021) databases. Starting from the DpGRX-FDR1 sequence, other sequences were retrieved by blastP analyses either from the Genbank database or from the JGI-Integrated microbial genomes and microbiomes portal (https: / /img.jgi.doe.gov/, accessed on 30 November 2021). Regular amino acid sequence alignments were performed using ClustalOmega, whereas structurebased sequence alignments were generated with mTM-align. The model structure of the RBX protein from D. psychrophila (GenBanK ID CAG37642) was generated ab initio with ColabFold server [32]. 
Supplementary Materials: The following are available online at https:/ / www.mdpi.com/article/ 10.3390/inorganics10020024/s1, Figure S1: UV-visible absorption spectrum of the anaerobicallypurified GRX domain of DpGRX-FDR, Figure S2: Structure-based sequence alignment of the GRXlike domain of DpGRX-FDR1 with its structural homologs and spinach TRX-f and TRX-m, Figure S3: Structure-based sequence alignment of SynFTRc and FDR domains of MaFDR-RBX and DpGRXFDR1 highlighting their common regions. Table S1: Primers used in this study for PCR cloning.

Author Contributions: Conceptualization, J.C., N.R. and C.D.; methodology, F.Z., S.M.; validation, J.C., N.R. and C.D.; formal analysis, F.Z.; investigation, F.Z., N.R., C.D.; data curation, J.C., N.R. and C.D.; writing—original draft preparation, N.R. and C.D.; writing-review and editing, N.R. and C.D. All authors have read and agreed to the published version of the manuscript.

Funding: This research received no external funding.

Institutional Review Board Statement: Not applicable.

Informed Consent Statement: Not applicable.

Data Availability Statement: Data regarding the 3D structure of DpGRX-FDR can be located in the protein data bank under the pdb entry code 7PWE.

Acknowledgments: The authors appreciated the access to the "Plateforme de mesures de diffraction $\mathrm{X}^{\prime \prime}$ of the Universite de Lorraine. The authors thank staffs for beam time and help during data collection on Proxima1 beamline at SOLEIL synchrotron (Gif-sur-Yvette, France) and on FIP-BM30A beamline at the ESRF (Grenoble, France). They also thank Michael K. Johnson and Tamanna Azam (Univ. of Georgia, USA) for technical and scientific exchanges.

Conflicts of Interest: The authors declare no conflict of interest.

\section{References}

1. Chibani, K.; Couturier, J.; Selles, B.; Jacquot, J.-P.; Rouhier, N. The Chloroplastic Thiol Reducing Systems: Dual Functions in the Regulation of Carbohydrate Metabolism and Regeneration of Antioxidant Enzymes, Emphasis on the Poplar Redoxin Equipment. Photosyn. Res. 2010, 104, 75-99. [CrossRef] [PubMed]

2. Yoshida, K.; Hisabori, T. Distinct Electron Transfer from Ferredoxin-Thioredoxin Reductase to Multiple Thioredoxin Isoforms in Chloroplasts. Biochem. J. 2017, 474, 1347-1360. [CrossRef] [PubMed]

3. Jacquot, J.-P.; Eklund, H.; Rouhier, N.; Schürmann, P. Structural and Evolutionary Aspects of Thioredoxin Reductases in Photosynthetic Organisms. Trends Plant. Sci. 2009, 14, 336-343. [CrossRef]

4. Dai, S.; Schwendtmayer, C.; Schürmann, P.; Ramaswamy, S.; Eklund, H. Redox Signaling in Chloroplasts: Cleavage of Disulfides by an Iron-Sulfur Cluster. Science 2000, 287, 655-658. [CrossRef] [PubMed]

5. Dai, S.; Friemann, R.; Glauser, D.A.; Bourquin, F.; Manieri, W.; Schürmann, P.; Eklund, H. Structural Snapshots along the Reaction Pathway of Ferredoxin-Thioredoxin Reductase. Nature 2007, 448, 92-96. [CrossRef]

6. Xu, X.; Schürmann, P.; Chung, J.-S.; Hass, M.A.S.; Kim, S.-K.; Hirasawa, M.; Tripathy, J.N.; Knaff, D.B.; Ubbink, M. Ternary Protein Complex of Ferredoxin, Ferredoxin:Thioredoxin Reductase, and Thioredoxin Studied by Paramagnetic NMR Spectroscopy. J. Am. Chem. Soc. 2009, 131, 17576-17582. [CrossRef]

7. Walters, E.M.; Garcia-Serres, R.; Jameson, G.N.L.; Glauser, D.A.; Bourquin, F.; Manieri, W.; Schürmann, P.; Johnson, M.K.; Huynh, B.H. Spectroscopic Characterization of Site-Specific [Fe4S4] Cluster Chemistry in Ferredoxin:Thioredoxin Reductase: Implications for the Catalytic Mechanism. J. Am. Chem. Soc. 2005, 127, 9612-9624. [CrossRef]

8. Jameson, G.N.L.; Walters, E.M.; Manieri, W.; Schürmann, P.; Johnson, M.K.; Huynh, B.H. Spectroscopic Evidence for Site Specific Chemistry at a Unique Iron Site of the $[4 \mathrm{Fe}-4 \mathrm{~S}]$ Cluster in Ferredoxin:Thioredoxin Reductase. J. Am. Chem. Soc. 2003, 125, 1146-1147. [CrossRef] [PubMed]

9. Balsera, M.; Uberegui, E.; Susanti, D.; Schmitz, R.A.; Mukhopadhyay, B.; Schürmann, P.; Buchanan, B.B. Ferredoxin:Thioredoxin Reductase (FTR) Links the Regulation of Oxygenic Photosynthesis to Deeply Rooted Bacteria. Planta 2013, 237, 619-635. [CrossRef]

10. Wei, Y.; Li, B.; Prakash, D.; Ferry, J.G.; Elliott, S.J.; Stubbe, J. A Ferredoxin Disulfide Reductase Delivers Electrons to the Methanosarcina barkeri Class III Ribonucleotide Reductase. Biochemistry 2015, 54, 7019-7028. [CrossRef]

11. Kumar, A.K.; Kumar, R.S.S.; Yennawar, N.H.; Yennawar, H.P.; Ferry, J.G. Structural and Biochemical Characterization of a Ferredoxin: Thioredoxin Reductase-like Enzyme from Methanosarcina acetivorans. Biochemistry 2015, 54, 3122-3128. [CrossRef] [PubMed]

12. Prakash, D.; Walters, K.A.; Martinie, R.J.; McCarver, A.C.; Kumar, A.K.; Lessner, D.J.; Krebs, C.; Golbeck, J.H.; Ferry, J.G. Toward a Mechanistic and Physiological Understanding of a Ferredoxin:Disulfide Reductase from the Domains Archaea and Bacteria. J. Biol. Chem. 2018, 293, 9198-9209. [CrossRef] [PubMed] 
13. Yenugudhati, D.; Prakash, D.; Kumar, A.K.; Kumar, R.S.S.; Yennawar, N.H.; Yennawar, H.P.; Ferry, J.G. Structural and Biochemical Characterizations of Methanoredoxin from Methanosarcina acetivorans, a Glutaredoxin-Like Enzyme with Coenzyme MDependent Protein Disulfide Reductase Activity. Biochemistry 2016, 55, 313-321. [CrossRef] [PubMed]

14. Rabus, R.; Ruepp, A.; Frickey, T.; Rattei, T.; Fartmann, B.; Stark, M.; Bauer, M.; Zibat, A.; Lombardot, T.; Becker, I.; et al. The Genome of Desulfotalea psychrophila, a Sulfate-Reducing Bacterium from Permanently Cold Arctic Sediments. Environ. Microbiol. 2004, 6, 887-902. [CrossRef] [PubMed]

15. Couturier, J.; Koh, C.S.; Zaffagnini, M.; Winger, A.M.; Gualberto, J.M.; Corbier, C.; Decottignies, P.; Jacquot, J.-P.; Lemaire, S.D.; Didierjean, C.; et al. Structure-Function Relationship of the Chloroplastic Glutaredoxin S12 with an Atypical WCSYS Active Site. J. Biol. Chem. 2009, 284, 9299-9310. [CrossRef] [PubMed]

16. Mesecke, N.; Mittler, S.; Eckers, E.; Herrmann, J.M.; Deponte, M. Two Novel Monothiol Glutaredoxins from Saccharomyces cerevisiae Provide Further Insight into Iron-Sulfur Cluster Binding, Oligomerization, and Enzymatic Activity of Glutaredoxins. Biochemistry 2008, 47, 1452-1463. [CrossRef] [PubMed]

17. Chibani, K.; Tarrago, L.; Schürmann, P.; Jacquot, J.-P.; Rouhier, N. Biochemical Properties of Poplar Thioredoxin z. FEBS Lett. 2011, 585, 1077-1081. [CrossRef]

18. Couturier, J.; Przybyla-Toscano, J.; Roret, T.; Didierjean, C.; Rouhier, N. The Roles of Glutaredoxins Ligating Fe-S Clusters: Sensing, Transfer or Repair Functions? Biochim. Biophys. Acta 2015, 1853, 1513-1527. [CrossRef]

19. Berndt, C.; Christ, L.; Rouhier, N.; Mühlenhoff, U. Glutaredoxins with Iron-Sulphur Clusters in Eukaryotes-Structure, Function and Impact on Disease. Biochim. Biophys. Acta Bioenerg. 2020, 1862, 148317. [CrossRef]

20. Rouhier, N.; Lemaire, S.D.; Jacquot, J.-P. The Role of Glutathione in Photosynthetic Organisms: Emerging Functions for Glutaredoxins and Glutathionylation. Annu. Rev. Plant. Biol. 2008, 59, 143-166. [CrossRef]

21. Nathaniel, C.; Wallace, L.A.; Burke, J.; Dirr, H.W. The Role of an Evolutionarily Conserved Cis-Proline in the Thioredoxin-like Domain of Human Class Alpha Glutathione Transferase A1-1. Biochem. J. 2003, 372, 241-246. [CrossRef] [PubMed]

22. Holm, L.; Laakso, L.M. Dali Server Update. Nucleic Acids Res. 2016, 44, W351-W355. [CrossRef] [PubMed]

23. Krissinel, E.; Henrick, K. Secondary-Structure Matching (SSM), a New Tool for Fast Protein Structure Alignment in Three Dimensions. Acta Crystallogr. D Biol. Crystallogr. 2004, 60, 2256-2268. [CrossRef] [PubMed]

24. Røhr, Å.K.; Hammerstad, M.; Andersson, K.K. Tuning of Thioredoxin Redox Properties by Intramolecular Hydrogen Bonds. PLoS ONE 2013, 8, e69411. [CrossRef] [PubMed]

25. Stehr, M.; Schneider, G.; Aslund, F.; Holmgren, A.; Lindqvist, Y. Structural Basis for the Thioredoxin-like Activity Profile of the Glutaredoxin-like NrdH-Redoxin from Escherichia coli. J. Biol. Chem. 2001, 276, 35836-35841. [CrossRef]

26. Van Laer, K.; Dziewulska, A.M.; Fislage, M.; Wahni, K.; Hbeddou, A.; Collet, J.-F.; Versées, W.; Mateos, L.M.; Tamu Dufe, V.; Messens, J. NrdH-Redoxin of Mycobacterium Tuberculosis and Corynebacterium Glutamicum Dimerizes at High Protein Concentration and Exclusively Receives Electrons from Thioredoxin Reductase. J. Biol. Chem. 2013, 288, 7942-7955. [CrossRef]

27. Susanti, D.; Wong, J.H.; Vensel, W.H.; Loganathan, U.; DeSantis, R.; Schmitz, R.A.; Balsera, M.; Buchanan, B.B.; Mukhopadhyay, B. Thioredoxin Targets Fundamental Processes in a Methane-Producing Archaeon, Methanocaldococcus jannaschii. Proc. Natl. Acad. Sci. USA 2014, 111, 2608-2613. [CrossRef]

28. Jung, H.-C.; Lim, J.K.; Yang, T.-J.; Kang, S.G.; Lee, H.S. Direct Electron Transfer between the FrhAGB-Encoded Hydrogenase and Thioredoxin Reductase in the Nonmethanogenic Archaeon Thermococcus onnurineus NA1. Appl. Environ. Microbiol. 2020, 86, e02630-19. [CrossRef]

29. Juniar, L.; Tanaka, H.; Yoshida, K.; Hisabori, T.; Kurisu, G. Structural Basis for Thioredoxin Isoform-Based Fine-Tuning of Ferredoxin-Thioredoxin Reductase Activity. Protein Sci. 2020, 29, 2538-2545. [CrossRef]

30. McCarver, A.C.; Lessner, D.J. Molecular Characterization of the Thioredoxin System from Methanosarcina acetivorans. FEBS J. 2014, 281, 4598-4611. [CrossRef]

31. Séry, A.; Housset, D.; Serre, L.; Bonicel, J.; Hatchikian, C.; Frey, M.; Roth, M. Crystal Structure of the Ferredoxin I from Desulfovibrio africanus at 2.3 A Resolution. Biochemistry 1994, 33, 15408-15417. [CrossRef] [PubMed]

32. Mirdita, M.; Schütze, K.; Moriwaki, Y.; Heo, L.; Ovchinnikov, S.; Steinegger, M. ColabFold—Making Protein Folding Accessible to All. bioRxiv 2021, 1-8. [CrossRef]

33. Kabsch, W. XDS. Acta Crystallogr. D Biol. Crystallogr. 2010, 66, 125-132. [CrossRef] [PubMed]

34. Liebschner, D.; Afonine, P.V.; Baker, M.L.; Bunkóczi, G.; Chen, V.B.; Croll, T.I.; Hintze, B.; Hung, L.W.; Jain, S.; McCoy, A.J.; et al. Macromolecular Structure Determination Using X-rays, Neutrons and Electrons: Recent Developments in Phenix. Acta Crystallogr. D Struct. Biol. 2019, 75, 861-877. [CrossRef]

35. Cowtan, K. The Buccaneer Software for Automated Model Building. 1. Tracing Protein Chains. Acta Crystallogr. D Biol. Crystallogr. 2006, 62, 1002-1011. [CrossRef]

36. Smart, O.S.; Womack, T.O.; Flensburg, C.; Keller, P.; Paciorek, W.; Sharff, A.; Vonrhein, C.; Bricogne, G. Exploiting Structure Similarity in Refinement: Automated NCS and Target-Structure Restraints in BUSTER. Acta Crystallogr. D Biol. Crystallogr. 2012, 68, 368-380. [CrossRef]

37. Emsley, P.; Lohkamp, B.; Scott, W.G.; Cowtan, K. Features and Development of Coot. Acta Crystallogr. D Biol. Crystallogr. 2010, 66, 486-501. [CrossRef] 